\title{
Hepatic Lipase Release is Inhibited by a Purinergic Induction of Autophagy
}

\author{
Cynthia Chatterjee Daniel L. Sparks
}

Atherosclerosis, Genetics and Cell Biology Group, University of Ottawa Heart Institute, Ottawa, Ontario, Canada

\section{Key Words}

Hepatic lipase $\cdot \mathrm{HDL} \cdot$ Nucleotides $•{\mathrm{P} 2 \mathrm{Y}_{13}}_{13}$ Purinergic signaling • Autophagy

\begin{abstract}
Background/Aims: We have shown that extracellular adenosine diphosphate (ADP) affects lipoprotein secretion from liver cells by stimulating cellular autophagic degradation. In this study, we investigated the effect of ADP and cellular autophagy on hepatic lipase $(\mathrm{HL})$ release from human liver cells. Methods/Results: Depletion of media serum stimulates an autophagic response in liver cells, which parallels an 8-fold increase in the release of ADP into the media and a complete inhibition of HL release. Treatment of cells with exogenous ADP stimulates cellular autophagy and also blocks HL release. Treatment with the autophagic stimulant and proteasomal inhibitor, ALLN $(25 \mu \mathrm{M})$, reduces cellular HL levels and blocks HL release at $4 \mathrm{~h}$. In contrast, treatment with the autophagy inhibitor, 3-methyladenine (3-MA) (5 mM), increases cellular HL levels and stimulates HL release. ADP acts through the G-protein coupled receptor, $\mathrm{P} 2 \mathrm{Y}_{13^{\prime}}$ to stimulate autophagy. siRNA-targeted reduction in $\mathrm{P} 2 \mathrm{Y}_{13}$ protein expression stimulates the release of $\mathrm{HL}$ by 5 to 8 -fold, while overexpression of $\mathrm{P} 2 \mathrm{Y}_{13}$ blocks $\mathrm{HL}$ release. $\mathrm{HL}$ release from liver cells is therefore inhibited by a purinergic induction of autophagy. To evaluate the effect of extracellular ADP on the processing of $\mathrm{HL}$, we expressed a $\mathrm{V} 5$-epitope tag-labeled $\mathrm{HL}$ (HL-V5) and then measured secretion, uptake and degradation. Two isoforms of HL-V5, at 62 and $68 \mathrm{kDa}$, are released from HepG2 cells, but only the $62 \mathrm{kDa}$ protein undergoes reuptake / internalization. The $62 \mathrm{kDa} \mathrm{HL}-\mathrm{V} 5$ isoform progressively accumulates in the cell over $24 \mathrm{~h}$, with no detectible modification or degradation. Treatment of liver cells with ADP has no effect on HL-V5 internalization or degradation at $30 \mathrm{~min}$ and $4 \mathrm{~h}$. Conclusion: These studies show that extracellular nucleotides act to prevent $\mathrm{HL}$ accumulation in the media by stimulating cellular autophagic degradation and blocking $\mathrm{HL}$ release.
\end{abstract}

Copyright $@ 2014$ S. Karger AG, Basel 
Chatterjee/Sparks: Nucleotides, Autophagy, and Hepatic Lipase

\section{Introduction}

Hypertriglyceridemia is a consequence of insulin resistance [1] and is due to an overproduction and impaired degradation of triglyceride (TG)-rich postprandial lipoproteins [2, 3]. Hepatic lipase (HL) plays a central role clearing TG-rich very-low lipoproteins (VLDL) from the circulation [4] and HL lipolytic function may be impaired in insulin resistance [5, 6]. The clearance of VLDL from the circulation is impaired in insulin resistance and VLDL levels are elevated $[5,7]$.

Hypertriglyceridemia and insulin resistance may be associated with abnormal purinergic signaling. Studies show that extracellular nucleotides disrupt insulin signaling and glucose metabolism [8,9] and perturb hepatic lipoprotein secretion [10]. Extracellular nucleotide levels in the bloodstream are regulated by ecto-enzymes that degrade nucleotides. A deficiency in the endonucleotidase, CD39/ENTPD1, has been shown to cause insulin resistance and hypertriglyceridemia in mice [11] and polymorphisms in the CD39 gene are associated with type 2 diabetes [12].

Extracellular nucleotides uniquely affect lipoprotein metabolism in liver cells. Lipoprotein secretion is regulated by cellular proteolytic pathways and nucleotides coregulate proteasomal degradation and cellular autophagy [10]. Consequently, the nucleotide, adenosine diphosphate (ADP), stimulates hepatic apoB100 secretion from liver cells and blocks high-density lipoprotein (HDL) secretion. HDL secretion from the liver is therefore regulated by autophagy and ADP acts through the purinergic G-protein coupled receptor, P2Y ${ }_{13}$, to stimulate the autophagic degradation of apoA-I [10].

Previous work has shown that the metabolism of apoA-I in liver cells directly affects the secretion of HL. Factors that stimulate apoA-I secretion from liver cells have a similar effect on the secretion of HL $[13,14]$. Since apoA-I secretion is suppressed by a purinergic stimulation in autophagy, a similar consequence to HL release would be expected. The present study shows that HL release from liver cells is also inhibited by nucleotide-induced autophagy and purinergic signaling through $\mathrm{P}_{2} \mathrm{Y}_{13}$. HL release is stimulated by autophagic inhibitors and suppression of $\mathrm{P} 2 \mathrm{Y}_{13}$ expression. The work shows that a modulation of HL release is not associated with extracellular HL recycling, but a consequence of cellular proteolytic degradation and secretion pathways. Extracellular nucleotides may consequently perturb the catabolism of TG-rich lipoproteins by decreasing HL release.

\section{Materials and Methods}

\section{Reagents}

Dilinoleoylphosphatidylcholine (DLPC) was obtained from Avanti Polar Lipids (Alabaster, AL). Adenosine 5'-diphosphate sodium salt (ADP), the proteasomal inhibitor, N-Acetyl-L-leucyl-L-leucyl-Lnorleucinal (ALLN), and the PI3 kinase inhibitor, 3-methyladenine (3-MA) were purchased from SigmaAldrich (Oakville, ON). The antibody to $\mathrm{P}_{2} \mathrm{Y}_{13}$ was obtained from Abcam (Cambridge, MA). The human hepatic lipase antibody was obtained from Santa Cruz Biotechnology Inc. (Santa Cruz, CA), the V5 antibody was from Invitrogen Corporation (Burlington, $\mathrm{ON}$ ), and the $\beta$-actin antibody was obtained from Cell Signaling Technology (Danvers, MA). Affinity purified peroxidase linked sheep anti-mouse and donkey antirabbit antibodies were purchased from GE Healthcare (UK). All Stars Negative control small interference RNA (siRNA) was purchased from Qiagen (Mississauga, ON) and human P2Y ${ }_{13}$ siRNA were purchased from Thermo Scientific Dharmacon (Lafayette, CO). The pcDNA6-human HL-V5-6XHis plasmid construct was a kind gift from Dr. Miklos Peterfy (UCLA, Los Angeles, CA). Inhibitors were of analytical grade and were solubilized in dimethyl sulfoxide (DMSO) or sterile water as recommended by the manufacturer.

\section{Cells and Cell Culture}

Human hepatocarcinoma, HepG2, cells were regularly maintained in Dulbecco's modified Eagle medium (DMEM) (5g/L glucose) containing 10\% fetal bovine serum (FBS) and 1\% penicillin/streptomycin. Passages 4-10 were used and cells that were $80 \%$ confluent were treated with DLPC, nucleotides and/ 
or inhibitors for the indicated times and concentrations under serum-free conditions. Cell viability was evaluated after all treatment conditions.

Preparation of DLPC Micelles

DLPC micelles were prepared in DMSO by sonication as previously described [15]. Purity of all phospholipids was $>99 \%$.

\section{Quantification of nucleotide release}

Nucleotide release from liver cells was quantified using the bioluminescent Enzylight ${ }^{\mathrm{TM}}$ ADP Assay Kit (BioAssay Systems, Hayward, CA) and manufacturer's recommended protocols. The assay utilizes luciferase to convert ATP and D-luciferin to oxyluciferin and light. ATP and ADP concentrations were quantified by subtraction, before and after conversion of ADP to ATP. Liver cell media aliquots were harvested from $\sim 5 \mathrm{x}$ $10^{5}$ cells/well and then frozen at $-20^{\circ} \mathrm{C}$. Samples were thawed immediately prior to the assay and $20 \mu \mathrm{l} /$ well was transferred to a 96-well black luminometer plate. The luciferin-luciferase reagents were added to the samples and the luminescence was quantified in a luminometer (Promega Glomax, 96 well plate reader). Media nucleotide levels were unchanged after RT storage for $2 \mathrm{~h}$ or $-20^{\circ} \mathrm{C}$ storage for 6 months.

\section{Knockdown of Human P2Y13 by Small Interference RNA}

HepG2 cells were transiently transfected with All Stars Negative control siRNA from Qiagen (Mississauga, ON) or two different $\mathrm{P}_{2} \mathrm{Y}_{13}$ siRNA sequences (ACCUUCAUCAUCUACCUCAAAUU or GACACUCAUGCUUCCUUUCAAUU) from Thermo Scientific Dharmacon (Lafayette, CO), by reverse transfection using Lipofectamine 2000 (Invitrogen, Carlsbad, CA) in 12-well plates. In brief, complexes were prepared per manufacturer's specifications with a Lipofectamine 2000-to-siRNA volume-to-mole ratio of 2:40 ( $\mu \mathrm{L}: \rho \mathrm{mol})$ in $200 \mu \mathrm{L}$ of Opti-MEM I Reduced Serum Media (Invitrogen, Carlsbad, CA). LipofectaminesiRNA complexes were added to the cells immediately after the cells were seeded at a density of 500,000 cells/well in a volume of $1 \mathrm{~mL}$ of normal growth media containing 10\% FBS in the absence of penicillin/ streptomycin. The cells were treated with ADP or DLPC in serum-free DMEM $48 \mathrm{~h}$ after transfection. Cell media and lysate samples were harvested at the indicated timepoints for immunoblot analysis. Transfection of the control and test siRNA caused no cytotoxic effects.

Overexpression of Human P2Y13 by Plasmid

The pCMV6 vector containing the full length human $\mathrm{P}_{2} \mathrm{Y}_{13}$ cDNA was purchased from Origene (Rockville, MD). HepG2 cells were transiently transfected with control plasmid or the pCMV6-P2Y13 plasmid by reverse transfection using FuGENE HD (Roche Applied Science, Laval, QC). Complexes were prepared per manufacturer's instructions with a FuGENE HD-to-DNA volume-to-mass ratio of 6:2 ( $\mu \mathrm{L}$ to $\mu \mathrm{g}$ ) in $100 \mu \mathrm{L}$ of Opti-MEM I Reduced Serum Media (Invitrogen, Carlsbad, CA). HepG2 cells were trypsinized and seeded in 12-well plates at a density of 500,000 cells/well in a volume of $1 \mathrm{~mL}$ in normal growth media containing $10 \% \mathrm{FBS}$ in the absence of penicillin/streptomycin and then $50 \mu \mathrm{L}$ of the transfection complexes were immediately added to the suspended cells. The cells were treated with ADP or DLPC in serum-free DMEM 48h after transfection. Cell media and lysate samples were harvested at the indicated timepoints for immunoblot analysis. Transfection of the control and test plasmid caused no cytotoxic effects.

\section{Immunoblot Analysis}

After treatment for the indicated timepoints, cells were washed twice with ice-cold PBS. Cells were lysed in NP-40 lysis buffer (Biosource, Camarillo, CA) supplemented with 1mM PMSF and 1X protease inhibitor cocktail (Sigma, Saint Louis, MO). Cell protein concentrations were determined by the BCA Protein Assay (Thermo Fisher Scientific, Waltham, MA). Cell lysate samples containing equal total protein $(30 \mu \mathrm{g})$ were separated by SDS-PAGE and analyzed by Western blot using specific antibodies to HL, V5, and $\beta$-actin. Blots were exposed using the Alpha Innotech FluorChem ${ }^{\mathrm{TM}} \mathrm{HD}$ Imager and band intensities were quantified with the Alpha Ease $\mathrm{FC}^{\mathrm{TM}}$ software.

\section{HL-V5 Endocytosis Assay}

HepG2 cells were transiently transfected with the pcDNA6-human HL-V5-6XHis plasmid construct obtained from Dr. Peterfy (UCLA, Los Angeles, CA) by reverse transfection using FuGENE HD (Roche Applied 
Science, Laval, QC) as described for $\mathrm{P}_{2} \mathrm{Y}_{13}$ overexpression. The conditioned media containing the secreted HL-V5 was collected $48 \mathrm{~h}$ after transfection and pooled. Wildtype (untransfected) HepG2 cells were either pre-treated with $100 \mu \mathrm{M}$ ADP or left untreated for $30 \mathrm{~min}$ in serum-free DMEM. HL-V5 conditioned media was then added to the pre-treated cells for either $30 \mathrm{~min}$ or $4 \mathrm{~h}$ for endocytosis. Cells were then harvested to determine the total cell association or internalization of HL-V5. Cells for total cell association were washed gently in PBS and then lysed, whereas cells for internalization were acid washed twice with $150 \mathrm{mM} \mathrm{NaCl}$ and $10 \mathrm{mM}$ acetic acid at pH 3.5 as previously described in [16]. Cell media and lysate samples were then immunoblotted and probed for V5.

\section{Statistical Analysis}

Values are shown as Mean \pm SD for at least 3 independent experiments and $P<0.05$ was considered significant. Differences between mean values were evaluated by one-way analysis of variance (ANOVA) on ranks by a pairwise multiple comparison using the Student-Newman-Keuls post-hoc test (SigmaStat; Systat Software, Inc., San Jose, CA).

\section{Results}

Nucleotide release, autophagy and $H L$

Extracellular nucleotides block HDL secretion from liver cells by stimulating autophagic proteolytic degradation pathways [10]. Autophagy is therefore affected by autocrine/ paracrine signaling and liver cells are known to release nucleotides into the extracellular space. Serum deprivation is well known to stimulate cellular autophagy $[17,18]$ and we now show that serum deprivation also stimulates nucleotide release from liver cells. Extracellular ADP levels may therefore play a role in the propagation of autophagy. Nucleotide levels in the media of confluent human liver cells were quantified by a bioluminescent Enzylight ${ }^{\mathrm{TM}}$ assay and shown to be in low [nM], with basal nucleotide levels averaging 15 nM (Fig. 1A). A change in the culture medium to a media containing serum and glucose $11 \% \mathrm{FBS}, 5 \mathrm{mM}$ glucose) had little effect on extracellular ATP levels, but more than doubles ADP levels by 30 minutes. Changing the media to a serum deficient (no FBS, $5 \mathrm{mM}$ glucose) media also has no effect on ATP, but increases ADP levels 8-fold (Fig. 1A). Cellular levels of the autophagic marker protein, LC3-II, were unaffected when cell media contained serum, but increased 2.5fold by 60 min when culture media was devoid of serum (Fig. 1B). Depletion of media serum also completely blocked the release of HL from the liver cells and reduced intracellular HL levels by $20 \%$ (Fig. 1C).

\section{$H L$ release and cellular autophagy}

Both HDL and HL release from liver cells appear to be blocked by a nucleotide induction of cellular autophagy. We previously showed that ADP acts through autophagic pathways to inhibit HDL secretion [10] and Fig. 2 shows that ADP stimulates autophagy and blocks HL release. Treatment of liver cells with ADP $(100 \mu \mathrm{M})$ significantly increases LC3-II levels at 4 hours (Fig. 2A), blocks HL release and accumulation in the media at $24 \mathrm{~h}$, and inhibits the induction of HL release by DLPC (Fig. 2B). ADP may therefore block HL release from liver cells by stimulating autophagic proteolytic degradation pathways. ADP stimulates autophagy and increases cellular LC3-II levels similar to the proteasomal inhibitor / autophagy stimulant, ALLN [10]. ALLN has a similar inhibitory effect on HL release as that observed with HDL. ALLN significantly reduced HL release at $4 \mathrm{~h}$ (Fig. 3A) and reduced cellular HL levels by $\sim 35 \%$ (Fig. 3B). ADP and ALLN therefore stimulate autophagic degradation and decrease the total HL mass (media+cellular), in much the same manner to that previously reported for apoA-I [10].

To determine how inhibition of autophagy may affect HL release, we evaluated the effect of the autophagy inhibitor, 3-methyladenine (3-MA). Treatment of liver cells with 3-MA ( $5 \mathrm{mM}$ ) significantly increased HL release after $4 \mathrm{~h}$, while treatment with both ADP and 3-MA blocked the HL release stimulatory effect of 3-MA (Fig. 4A). Treatment with 3-MA also 


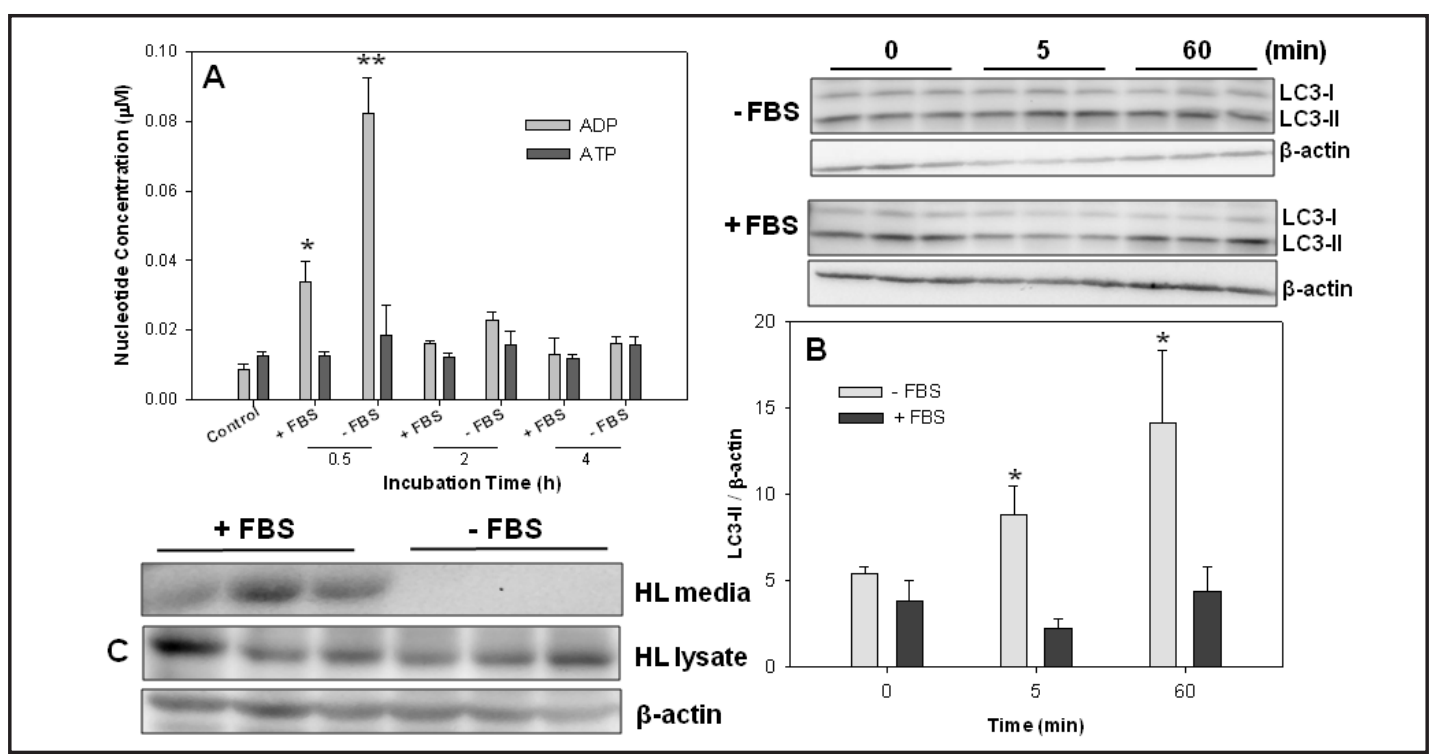

Fig. 1. Serum deprivation stimulates nucleotide release and cellular autophagy and blocks HL release. Human liver cells were cultured to near confluence in nutrient complete media. The media was changed to a serum competent ( + FBS = $5 \mathrm{mM}$ glucose, 1\% FBS) and deficient media ( $-\mathrm{FBS}=5 \mathrm{mM}$ glucose) and then media aliquots were sampled over time. (A) Media ATP\&ADP concentrations were determined by bioluminescence assay and values are expressed as mean $\pm \mathrm{SD}$ of 3 independent experiments. ${ }^{*} \mathrm{P}<0.01$ vs control $(\mathrm{t}=0)$ $* * \mathrm{P}<0.001 \mathrm{vs}+\mathrm{FBS}(\mathrm{t}=0.5 \mathrm{~h})(\mathrm{B})$ Cell lysates were immunoblotted for LC3 and $\beta$-actin. Histograms represent band densitometry analysis of LC3-II concentration in the cell lysate normalized to $\beta$-actin and expressed as mean \pm SD of 3 independent experiments. ${ }^{*} \mathrm{P}=0.05$ vs. control (C) Cell lysates and conditioned media were collected after $2 \mathrm{~h}$ and immunoblotted for HL. The immunoblots are representative of 3 independent experiments that were performed in triplicate.

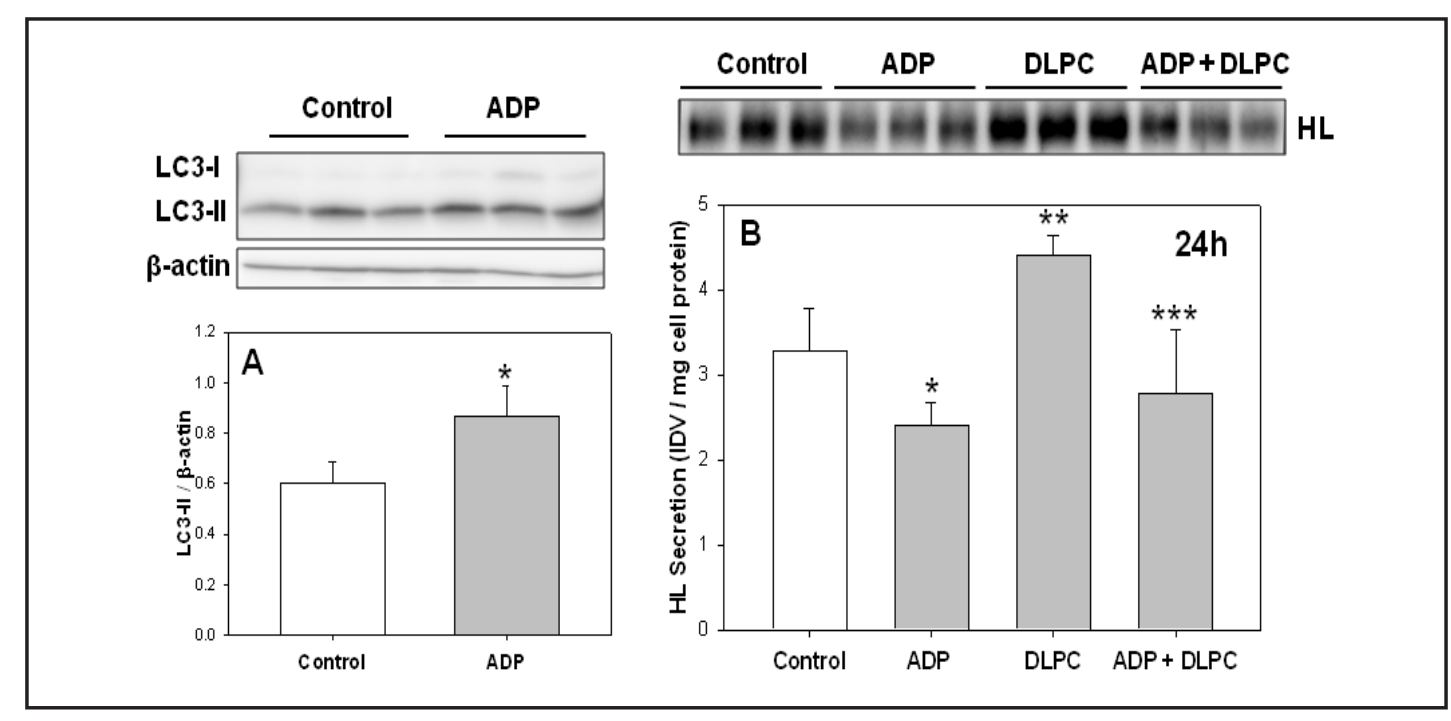

Fig. 2. Extracellular ADP stimulates autophagy and blocks HL release. HepG2 cells were pre-treated with $100 \mu \mathrm{M}$ adenosine diphosphate (ADP) for $30 \mathrm{~min}$. and then incubated with and without $12 \mu \mathrm{M}$ DLPC in serum-free media. (A) Cell lysates were collected after $4 \mathrm{~h}$ and immunoblotted for LC3 and $\beta$-actin. Histograms represent band densitometry analysis of LC3-II concentration in the cell lysate normalized to $\beta$-actin and expressed as mean \pm SD of 3 independent experiments. ${ }^{*} \mathrm{P}=0.05$ vs. control. (B) Conditioned media was collected after $24 \mathrm{~h}$ and immunoblotted for HL. Histograms represent band densitometry analysis of HL concentration in the media normalized to total cell protein and expressed as mean \pm SD of 3 independent experiments. ${ }^{*} \mathrm{P}=0.05$ vs. Control; ${ }^{* *} \mathrm{P}=0.01$ vs. Control; ${ }^{* * *} \mathrm{P}<0.05$ vs. DLPC. 


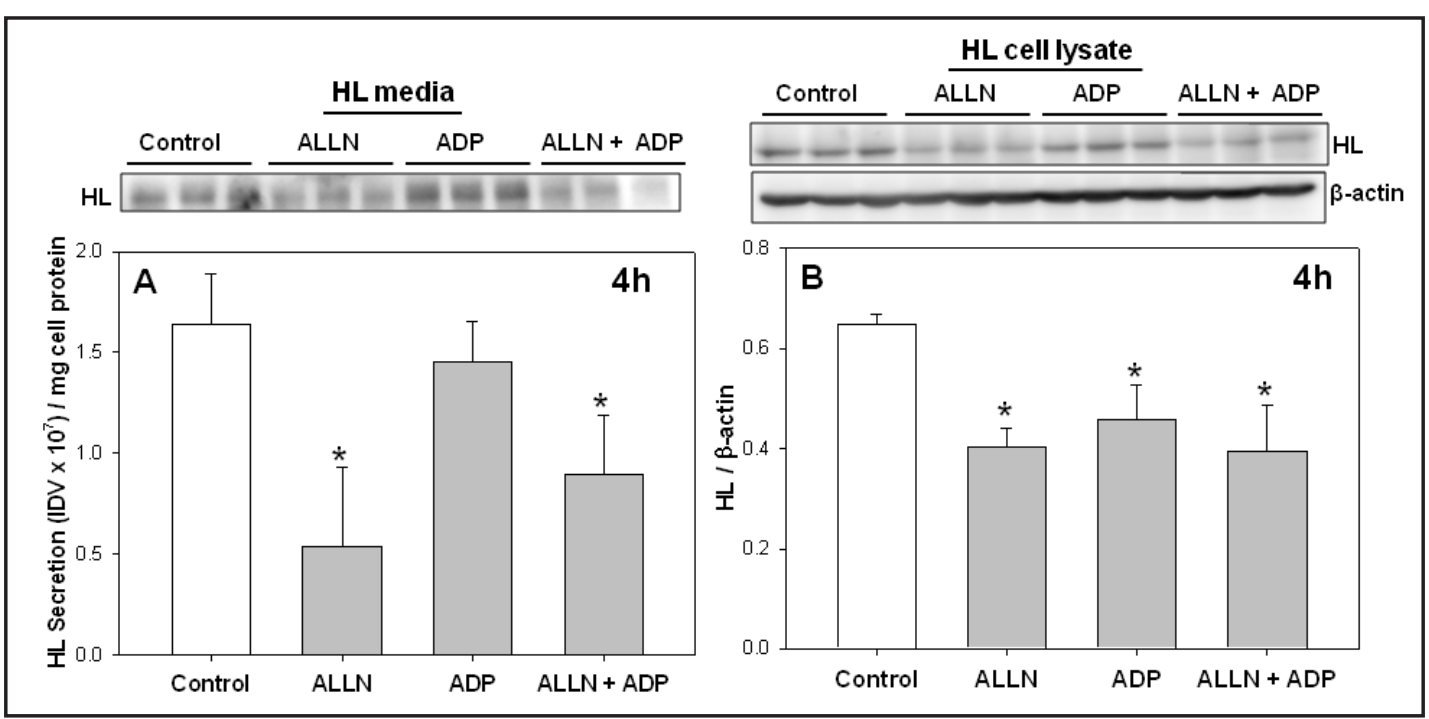

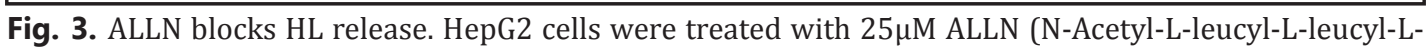
norleucinal) or $100 \mu \mathrm{M}$ adenosine diphosphate (ADP) for $4 \mathrm{~h}$ in serum-free DMEM media. (A) Conditioned media was collected and immunoblotted for HL. Histograms represent band densitometry analysis of HL concentration in the media normalized to total cell protein and expressed as mean \pm SD of 3 independent experiments performed in triplicate. ${ }^{*} \mathrm{P}<0.05$ vs. Control. (B) Cell lysates were collected and immunoblotted for HL. Histograms represent band densitometry analysis of HL expressed as mean \pm SD of 3 independent experiments performed in triplicate. ${ }^{*} \mathrm{P}<0.01$ vs. Control.
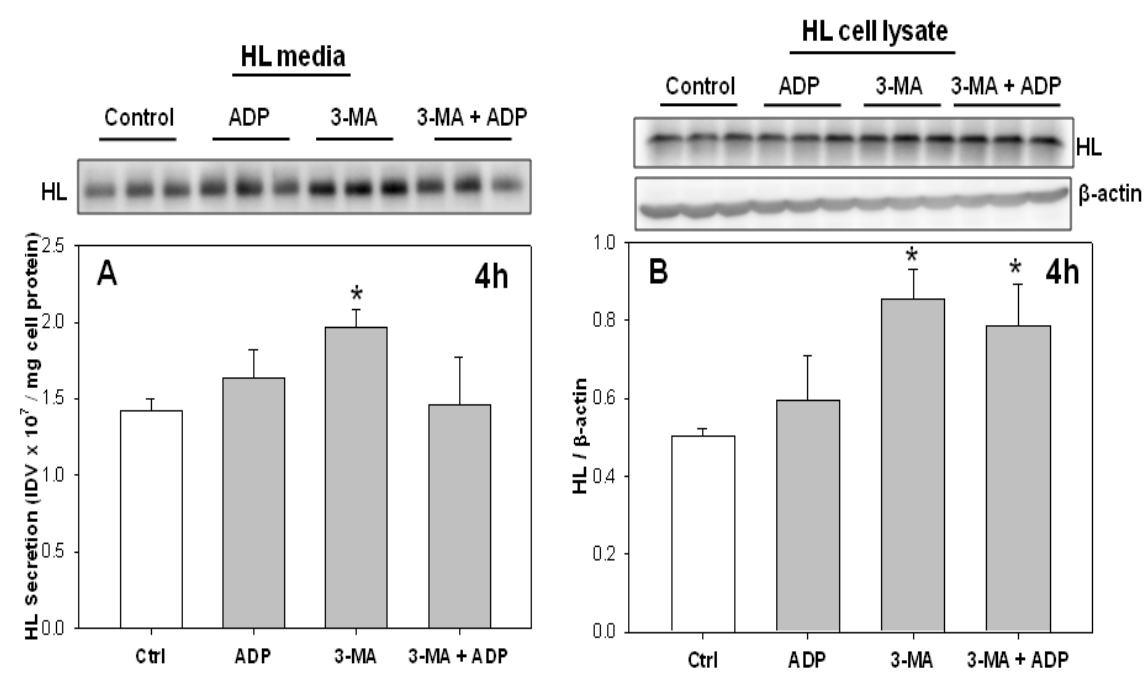

Fig. 4. The autophagy inhibitor, 3-methyladenine, increases HL release. HepG2 cells were treated with $5 \mathrm{mM}$ methyladenine (3-MA) or $100 \mu \mathrm{M}$ adenosine diphosphate (ADP) for $4 \mathrm{~h}$ in serum-free DMEM media. (A) Conditioned media was collected and immunoblotted for HL. Histograms represent band densitometry analysis of HL concentration in the media normalized to total cell protein and expressed as mean \pm SD of 3 independent experiments performed in triplicate. ${ }^{*} \mathrm{P}<0.05$ vs. Control. (B) Cell lysates were collected and immunoblotted for HL normalized to $\beta$-actin expressed as mean \pm SD of 3 independent experiments performed in triplicate. ${ }^{*} \mathrm{P}<0.01$ vs. Control.

significantly increased cellular levels of HL (Fig. 4B). This work confirms the view that both HDL and HL release are co-regulated [13] and inhibited by cellular autophagy [10]. 


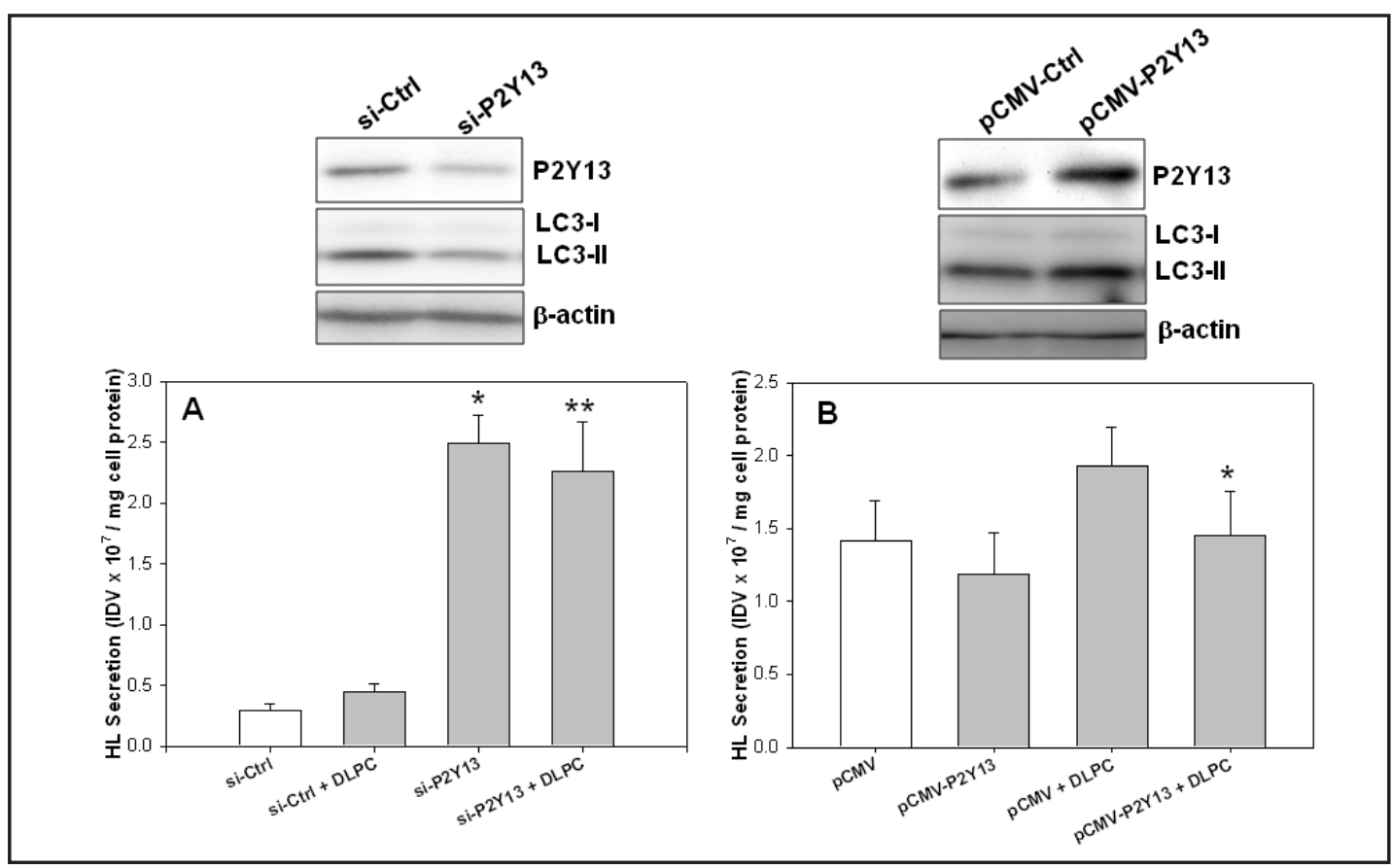

Fig. 5. $P 2 Y_{13}$ expression regulates HL release. (A) HepG2 cells were transfected with either a negative control siRNA (si-ctrl) or a siRNA against human P2Y ${ }_{13}$ (si-P2Y13). Cell lysates were collected 48h after transfection and immunoblotted for P2Y ${ }_{13}$, LC3 and $\beta$-actin (upper panels). Conditioned media was collected and immunoblotted for HL. Histograms represent band densitometry analysis of HL concentration in the media normalized to total cell protein and expressed as mean $\pm \mathrm{SD}$ of 3 independent experiments. ${ }^{*} \mathrm{P}<0.001$ vs si-Ctrl, ${ }^{* *} \mathrm{P}<0.001$ vs si-Ctrl + DLPC. (B) HepG2 cells were transfected with either a control pCMV plasmid

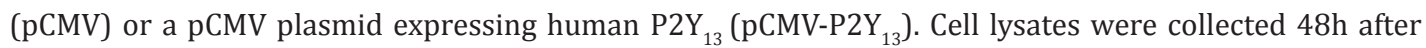
transfection and immunoblotted for $\mathrm{P}_{2} \mathrm{Y}_{13}$, LC3 and $\beta$-actin (upper panels). Conditioned media was collected and immunoblotted for HL. Histograms represent band densitometry analysis of HL concentration in the media normalized to total cell protein and expressed as mean \pm SD of 3 independent experiments. *P=0.05 vs pCMV+DLPC.

\section{Effect of P2Y13 expression on $H L$ release}

The G-protein coupled receptor, $\mathrm{P}_{2} \mathrm{Y}_{13}$, has been shown to regulate cellular autophagy in liver cells and extracellular ADP stimulates autophagy through activation of ${\mathrm{P} 2 \mathrm{Y}_{13}}_{10}[10]$. Experiments were therefore undertaken to determine the effect of $\mathrm{P}_{2} \mathrm{Y}_{13}$ expression on HL secretion from liver cells. Transfecting HepG2 cells with $\mathrm{P}_{2} \mathrm{Y}_{13}$ siRNA promotes a 50\% reduction in $\mathrm{P} 2 \mathrm{Y}_{13}$ and LC3-II protein expression and stimulates the secretion of HL by 5 to 8-fold (Fig. 5A). Conversely, $\mathrm{P}_{2} \mathrm{Y}_{13}$ overexpression decreased HL secretion similar to treatment with exogenous ADP. Transfecting HepG2 cells with the P2Y $\mathrm{Y}_{13}$-pCMV6 plasmid promotes an increase in $\mathrm{P}_{2} \mathrm{Y}_{13}$ and LC3-II expression and completely blocks the induction of HL secretion by DLPC (Fig. 5B). P2Y $\mathrm{Y}_{13}$ expression therefore appears to affect HL and HDL secretion similarly, by regulating cellular autophagy [10].

\section{Extracellular HL uptake and metabolism}

$\mathrm{P}_{2} \mathrm{Y}_{13}$ has been shown to stimulate the endocytosis of HDL [19] and therefore to determine the effect of ADP on HL endocytic pathways, the binding, uptake and metabolism of V5-epitope-tagged HL (HL-V5) was characterized. HL-V5 was isolated in cell media after transfection of HepG2 cells with a pcDNA6-HL-V5 expression vector [20]. Wild-type (untransfected) cells were then incubated with exogenous HL-V5 and the binding and internalization of HL-V5 was measured immunochemically. HepG2 cells secrete two different 
Fig. 6. The endocytic uptake of epitope-labeled HL in liver cells. HepG2 cells were transfected with either a control pCMV plasmid (pCMV) or a pCMV plasmid expressing Nterminus V5-epitope tagged human hepatic lipase (pCMVHL-V5) for 24h. Conditioned media containing HL-V5 was

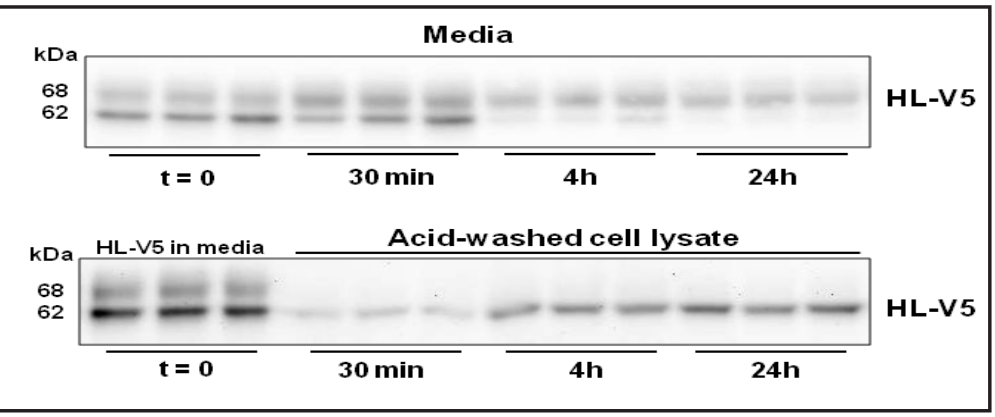
collected and then added to wildtype, untransfected HepG2 cells over a $24 \mathrm{~h}$ period to monitor the binding, internalization and re-secretion of HL. Both conditioned media (upper panel) and acid-washed cell lysates to measure internalization (lower panel) from the recipient HepG2 cells were collected at different timepoints $(0.5,4 \& 24 \mathrm{~h})$ and immunoblotted for HL-V5. The immunoblots are representative of 2 independent experiments that were performed in triplicate.

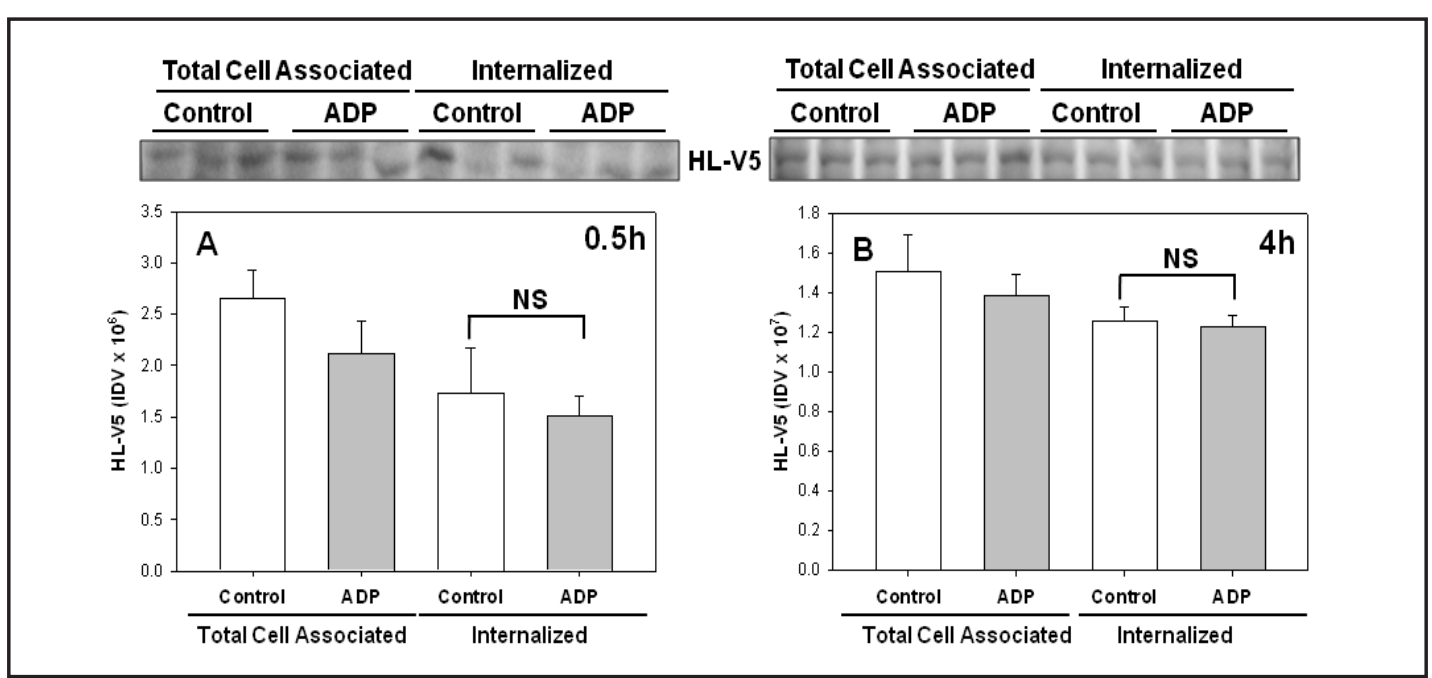

Fig. 7. The effect of ADP on HL endocytosis. (A\&B) HepG2 cells were pre-treated with $100 \mu \mathrm{M}$ ADP for $30 \mathrm{~min}$ prior to the addition of HL-V5 conditioned media for $0.5 \mathrm{~h}(\mathrm{~A})$ or $4 \mathrm{~h}(\mathrm{~B})$. Cell lysates were collected without acid-wash for total cell association (TCA) or with acid-wash for internalization, and immunoblotted for HL-V5. Histograms represent band densitometry analysis of HL-V5 total cell association (TCA) and internalization (Int) expressed as mean $\pm \mathrm{SD}$ of 2 independent experiments performed in triplicate. (NS = not significant).

species of HL-V5, at 62 and $68 \mathrm{kDa}$ and the V5 mAb detects both species equally (Fig. 6, $\mathrm{t}=0$ ). We have previously shown that HepG2 cells secrete two isoforms of HL [21] and earlier studies suggest the proteins differ in their extent of glycosylation [22].Figure 6 shows that only the $62 \mathrm{kDa}$ HL-V 5 can become re-associated and taken up by the cell. The $62 \mathrm{kDa}$ HL-V5 is progressively internalized over time and after $24 \mathrm{~h}$ the media becomes almost completely depleted of the protein (Fig. 6, upper panel). Concomitantly, the $62 \mathrm{kDa}$ HL is selectively internalized into HepG2 cells and accumulates unmodified in the cell over 24h. Internalized $62 \mathrm{kDa}$ HL-V5 was not degraded over time, but was retained intact in the cell for $24 \mathrm{~h}$ (Fig. 6 , lower panel). The effect of ADP on the metabolism of exogenous HL-V5 was then investigated. Treatment of HepG2 cells with $100 \mu \mathrm{M}$ ADP slightly reduced the total cell association of HLV5 at $0.5 \mathrm{~h}$ (Fig. 7A), but had no effect on HL-V5 endocytosis. Treatment with ADP had no effect on the internalization of HL-V5 at $0.5 \mathrm{~h}$ or $4 \mathrm{~h}$ (Fig. 7A\&B). No HL-V5 degradation was detectable after short or long-term incubations for control or ADP treated cells. 
Fig. 8. ADP stimulates autophagy and blocks HL release. Hepatic lipase (HL) release from liver cells is regulated by cellular autophagy. Serum deprivation stimulates the release of ADP to the extracellular milieu, which then acts through membrane $\mathrm{P}_{2} \mathrm{Y}_{13}$ receptors to initiate cellular autophagy and divert HL from secretory pathways to lysosomal degradation.

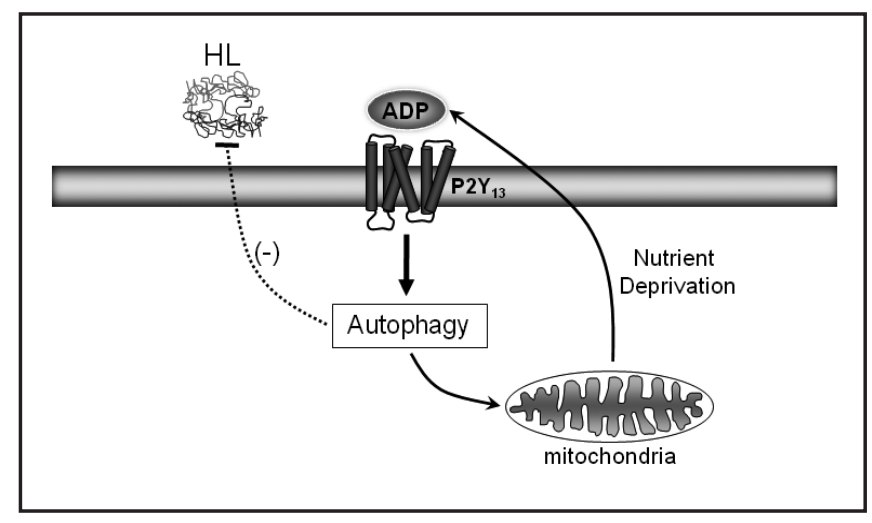

\section{Discussion}

Hypertriglyceridemia is a comorbidity of insulin resistance [1] and one that is thought to exacerbate perturbations in insulin signaling pathways that cause elevated blood glucose [23]. Elevations in blood triglyceride (TG) are a consequence of impaired TG-rich lipoprotein clearance [2] and over-production of VLDL [3]. Insulin resistance may also be associated with an increase in nucleotide release [24-26]. Increased circulating nucleotide levels may contribute to hypertriglyceridemia by increasing VLDL levels in the bloodstream $[10,11]$. Gene knockout studies in mice have shown that a deficiency in the NTPDase1 can cause elevated blood nucleotide levels, insulin resistance and hypertriglyceridemia [11].

VLDL-TG and apoB100 levels are elevated in insulin resistance [5, 7] and this may be partly a consequence of a stimulatory effect of extracellular nucleotides on hepatic VLDL secretion. Lipoprotein secretion is controlled by cellular proteolytic pathways and nucleotides act much like proteasomal inhibitors to block proteasomal degradation and stimulate autophagy [10]. Extracellular nucleotides, i.e. adenosine diphosphate (ADP), stimulate both apoB100 and apoE secretion from liver cells and thereby promote the accumulation of VLDL in the cell media [10].

Nucleotides may also promote VLDL accumulation by blocking VLDL clearance from the bloodstream. Hepatic lipase (HL) promotes the hydrolysis and clearance of VLDL from the circulation and thereby regulates the production of LDL [4]. Circulatory VLDL levels are elevated in insulin resistance, as a consequence of reduced HL lipolytic function and impaired clearance of VLDL $[5,6]$. We have previously shown that HL lipolytic function is regulated by HDL secretion from liver cells and by apolipoprotein exchange between HDL and VLDL [14]. HL release from liver cells is controlled by lysosomal degradation pathways [27] and therefore a nucleotide stimulation of autophagic-lysosomal degradation would be expected to reduce HL release (Fig. 8). The data illustrated inFigures 1-5 appear to support this view.

We previously showed that exogenously applied nucleotides can stimulate autophagy and block protein secretion from liver cells [10]. In this study we have attempted to show that factors that increase nucleotide release and accumulation in the media also affect autophagy and protein secretion. Our data has identified a linkage between nucleotide release and cellular autophagy, which may suggest that autophagy is affected by autocrine/paracrine signaling. Nucleotide release is stimulated by factors that stress the cell, such as a serum deprivation in media, which stimulates the release of ADP (Fig. 1A). ADP concentration doubles in the media after a change in media, but increases by orders of magnitude when media is deficient of FBS or other nutrients (data not shown). The ADP response to serum deprivation closely paralleled an autophagic response, as indicated by an increase in cellular LC3-II (Fig. 1B). Increased ADP release and autophagy also directly parallel a reduction in HL release (Figure 1C). This is consistent with previous work, which has shown that autophagy inhibits protein secretion $[17,18]$. However, while others have shown that serum deprivation initiates an autophagic response, this appears to be the first cited evidence that ADP release 
from a liver cell parallels the activation of autophagy. Further experimental work is needed to determine if extracellular nucleotides are required to promote an autocrine/paracrine modulation of cellular autophagy.

Exogenous nucleotides also block HL release. Treatment of human liver cells with ADP for $24 \mathrm{~h}$ blocks both basal and DLPC-induced HL release (Fig. 2), much the same as that observed with ADP on HDL secretion [10]. ADP significantly reduced cellular HL levels at 4h, much like the autophagic stimulator, ALLN (Fig. 3), but only ALLN significantly reduced HL release at $4 \mathrm{~h}$. We have previously shown that incubations of $>12$ hours are usually required to show changes in HL release $[13,14]$ and since both ADP and ALLN had a more pronounced inhibitory effect on HDL secretion at $4 \mathrm{~h}$ [10], this may suggest that cellular transport pathways for HDL and HL may differ. Conversely, the autophagic inhibitor, 3-MA stimulates HL release from liver cells (Fig. 4A) and significantly increases HL levels in the cell (Fig. 4B). This is strong evidence to suggest that HL release is sensitive to nucleotide-induced cellular autophagy and this may explain why chaperone proteins, i.e. lipase maturation factor 1 , are needed to protect HL from lysosomal degradation during cellular transport [28].

We showed that ADP acts through the membrane G-protein coupled receptor, $\mathrm{P}_{2} \mathrm{Y}_{13}$, to stimulate the autophagic degradation of apoA-I [10]. P2 $\mathrm{Y}_{13}$ expression was shown to directly correlate with LC3 expression. Since the metabolism of apoA-I in liver cells affects the release of HL [13], it would be expected that ADP may also act through $\mathrm{P}_{2} \mathrm{Y}_{13}$ to regulate HL release. In agreement with this view, $\mathrm{P}_{2} \mathrm{Y}_{13}$ expression affects $\mathrm{HL}$ release in much the same manner as that shown for HDL (Fig. 5). We previously showed that $\mathrm{P}_{2} \mathrm{Y}_{13}$ gene silencing completely blocked the effect of ADP on cell signaling, autophagy and HDL secretion [10]. We now show that a reduction in $\mathrm{P} 2 \mathrm{Y}_{13}$ expression potently increases HL release by 5 to 8-fold, while $\mathrm{P} 2 \mathrm{Y}_{13}$ over-expression suppresses HL release (Fig. 5A\&B). It is notable that gene silencing had a much greater effect on $\mathrm{HL}$ release than over-expression of $\mathrm{P}_{2} \mathrm{Y}_{13}$. Similar observations were made between $\mathrm{P} 2 \mathrm{Y}_{13}$ expression and HDL secretion [10]. This appears consistent with the view that intracellular degradation pathways are normally hyperactive and most intracellular HL is targeted to degradation [27]. HL release may therefore be less sensitive to stimulation in autophagic degradation, but very sensitive to inhibition of degradation. Our work has clearly shown that P2 $\mathrm{Y}_{13}$ expression controls cellular autophagy by directly affecting LC3 levels [10] and this new work provides further evidence that $\mathrm{P}_{2} \mathrm{Y}_{13}$ and autophagy regulate HL release (Fig. 8).

To determine if purinergic stimulation of autophagy affects extracellular HL uptake and degradation, we utilized an epitope-labeled HL construct to characterize HL endocytic pathways. HL-V5 was produced in HepG2 cells [27] and then used to track the metabolism of extracellular HL in untransfected cells. HepG2 cells produce two HL-V5 isoforms at $62 \mathrm{kDa}$ and $68 \mathrm{kDa}$, but only the smaller $62 \mathrm{kDa}$ species is taken up by the cell (Fig. 6). HL-V5 is readily internalized into HepG2 cells, but ADP does not affect the endocytosis of HL-V5 (Fig. 6\&7). Nor did ADP affect the degradation of the endocytosed HL-V5. Proteins that were endocytosed in control and ADP treatment conditions remained intact in the HepG2 cells for up to $24 \mathrm{~h}$. The work suggests that HL release is not associated with extracellular HL recycling, but a consequence of autophagic degradation in lysosomes.

Elevated circulating nucleotide levels and purinergic activation in insulin resistance may therefore perturb triglyceride metabolism [10, 29]. Circulating nucleotide levels are affected by nucleotide degradative enzymes and therefore, altered function of cellular nucleotidases may be implicated in insulin resistance and hyperlipidemia. Polymorphisms in the endonucleotidase, CD39, gene were shown to be associated with type 2 diabetes and diabetic nephropathy [12]. A suppression in CD39 expression was also shown to cause insulin resistance and hypertriglyceridemia in mice [11]. These studies support the view that abnormal purinergic signaling may contribute to insulin resistance and hypertriglyceridemia [29]. Purinergic inhibitors may therefore have therapeutic value to treat metabolic and cardiovascular disease $[30,31]$. Inhibition of $\mathrm{P}_{2} \mathrm{Y}_{12}$-dependent purinergic signaling pathways has shown significant cardiovascular therapeutic value [32, 33]. 
Chatterjee/Sparks: Nucleotides, Autophagy, and Hepatic Lipase

\section{Acknowledgements}

The work was supported by a grant from the Heart and Stroke Foundation of Canada to D.L.S. C.C. is the recipient of a Government of Ontario Graduate Scholarship.

\section{References}

1 Grundy SM: Hypertriglyceridemia, atherogenic dyslipidemia, and the metabolic syndrome. Am J Cardiol 1998;81:18B-25B.

$\nabla_{2}$ Taskinen MR: Hyperlipidaemia in diabetes. Baillieres Clin Endocrinol Metab 1990;4:743-775.

Adiels M, Olofsson SO, Taskinen MR, Boren J: Overproduction of very low-density lipoproteins is the hallmark of the dyslipidemia in the metabolic syndrome. Arterioscler Thromb Vasc Biol 2008;28:12251236.

4 Connelly PW, Maguire GF, Lee M, Little JA: Plasma lipoproteins in familial hepatic lipase deficiency. Arteriosclerosis 1990;10:40-48.

5 Taskinen MR, Packard CJ, Shepherd J: Effect of insulin therapy on metabolic fate of apolipoprotein Bcontaining lipoproteins in NIDDM. Diabetes 1990;39:1017-1027.

6 Pihlajamaki J, Karjalainen L, Karhapaa P, Vauhkonen I, Taskinen MR, Deeb SS, Laakso M: G-250A substitution in promoter of hepatic lipase gene is associated with dyslipidemia and insulin resistance in healthy control subjects and in members of families with familial combined hyperlipidemia. Arterioscler Thromb Vasc Biol 2000;20:1789-1795.

7 Annuzzi G, De NC, Iovine C, Patti L, Di ML, Coppola S, Del PS, Riccardi G, Rivellese AA: Insulin resistance is independently associated with postprandial alterations of triglyceride-rich lipoproteins in type 2 diabetes mellitus. Arterioscler Thromb Vasc Biol 2004;24:2397-2402.

8 Solini A, Chiozzi P, Morelli A, Passaro A, Fellin R, Di Virgillio F: Defective P2Y purinergic receptor function: A possible novel mechanism for impaired glucose transport. J Cell Physiol 2003;197:435-444.

-9 Amisten S, Meidute-Abaraviciene S, Tan C, Olde B, Lundquist I, Salehi A, Erlinge D: ADP mediates inhibition of insulin secretion by activation of P2Y13 receptors in mice. Diabetologia 2010;53:1927-1934.

10 Chatterjee C, Sparks DL: Extracellular nucleotides inhibit insulin receptor signaling, stimulate autophagy and control lipoprotein secretion. PLoS ONE 2012;7:e36916.

11 Enjyoji K, Kotani K, Thukral C, Blumel B, Sun X, Wu Y, Imai M, Friedman D, Csizmadia E, Bleibel W, Kahn BB, Robson SC: Deletion of cd39/entpd1 results in hepatic insulin resistance. Diabetes 2008;57:2311-2320.

-12 Friedman DJ, Talbert ME, Bowden DW, Freedman BI, Mukanya Y, Enjyoji K, Robson SC: Functional ENTPD1 polymorphisms in African Americans with diabetes and end-stage renal disease. Diabetes 2009;58:9991006.

13 Chatterjee C, Young EK, Pussegoda KA, Twomey EE, Pandey NR, Sparks DL: Hepatic high-density lipoprotein secretion regulates the mobilization of cell-surface hepatic lipase. Biochemistry 2009;48:59946001.

14 Chatterjee C, Sparks DL: Hepatic lipase, high density lipoproteins, and hypertriglyceridemia. Am J Pathol 2011;178:1429-1433.

15 Pandey NR, Renwick J, Misquith A, Sokoll K, Sparks DL: Linoleic Acid-Enriched Phospholipids Act through Peroxisome Proliferator-Activated Receptors alpha To Stimulate Hepatic Apolipoprotein A-I Secretion. Biochemistry 2008;47:1579-1587.

16 de Renzis S, Sonnichsen B, Zerial M: Divalent Rab effectors regulate the sub-compartmental organization and sorting of early endosomes. Nat Cell Biol 2002;4:124-133.

17 Ravikumar B, Sarkar S, Davies JE, Futter M, Garcia-Arencibia M, Green-Thompson ZW, Jimenez-Sanchez M, Korolchuk VI, Lichtenberg M, Luo S, Massey DC, Menzies FM, Moreau K, Narayanan U, Renna M, Siddiqi FH, Underwood BR, Winslow AR, Rubinsztein DC: Regulation of mammalian autophagy in physiology and pathophysiology. Physiol Rev 2010;90:1383-1435.

18 Kroemer G, Marino G, Levine B: Autophagy and the integrated stress response. Mol Cell 2010;40:280-293. 


\section{Cellular Physiology $\quad$ Cell Physiol Biochem 2014;33:883-894 and Biochemistry \\ Chatterjee/Sparks: Nucleotides, Autophagy, and Hepatic Lipase}

19 Jacquet S, Malaval C, Martinez LO, Sak K, Rolland C, Perez C, Nauze M, Champagne E, Terce F, Gachet C, Perret B, Collet X, Boeynaems JM, Barbaras R: The nucleotide receptor P2Y13 is a key regulator of hepatic high-density lipoprotein (HDL) endocytosis. Cell Mol Life Sci 2005;62:2508-2515.

20 Ben-Zeev 0, Doolittle MH: Maturation of hepatic lipase. Formation of functional enzyme in the endoplasmic reticulum is the rate-limiting step in its secretion. J Biol Chem 2004;279:6171-6181.

21 Ramsamy TA, Boucher J, Brown RJ, Yao Z, Sparks DL: HDL regulates the displacement of hepatic lipase from cell surface proteoglycans and the hydrolysis of VLDL triacylglycerol. J Lipid Res 2003;44:733-741.

22 Verhoeven AJ, Neve BP, Jansen H: Secretion and apparent activation of human hepatic lipase requires proper oligosaccharide processing in the endoplasmic reticulum. Biochem J 1999;337:133-140.

23 Giacca A, Xiao C, Oprescu AI, Carpentier AC, Lewis GF: Lipid-induced pancreatic beta-cell dysfunction: focus on in vivo studies. Am J Physiol Endocrinol Metab 2011;300:E255-E262.

24 Parodi J, Flores C, Aguayo C, Rudolph MI, Casanello P, Sobrevia L: Inhibition of nitrobenzylthioinosinesensitive adenosine transport by elevated D-glucose involves activation of P2Y2 purinoceptors in human umbilical vein endothelial cells. Circ Res 2002;90:570-577.

25 Solini A, Iacobini C, Ricci C, Chiozzi P, Amadio L, Pricci F, Di Mario U, Di Virgilio F, Pugliese G: Purinergic modulation of mesangial extracellular matrix production: role in diabetic and other glomerular diseases. Kidney Int 2005;67:875-885.

26 Nilsson J, Nilsson LM, Chen YW, Molkentin JD, Erlinge D, Gomez MF: High glucose activates nuclear factor of activated T cells in native vascular smooth muscle. Arterioscler Thromb Vasc Biol 2006;26:794-800.

27 Ben Zeev 0, Doolittle MH: Maturation of hepatic lipase. Formation of functional enzyme in the endoplasmic reticulum is the rate-limiting step in its secretion. J Biol Chem 2004;279:6171-6181.

-28 Doolittle MH, Neher SB, Ben-Zeev O, Ling-Liao J, Gallagher CM, Hosseini M, Yin F, Wong H, Walter P, Peterfy M: Lipase maturation factor LMF1, membrane topology and interaction with lipase proteins in the endoplasmic reticulum. J Biol Chem 2009;284:33623-33633.

29 Sparks DL, Chatterjee C: Purinergic Signaling, Dyslipidemia and Inflammatory Disease. Cell Physiol Biochem 2012;30:1333-1339.

30 Di Virgilio F, Solini A: P2 receptors: new potential players in atherosclerosis. Br J Pharmacol 2002;135:831842 .

-31 Erlinge D, Burnstock G: P2 receptors in cardiovascular regulation and disease. Purinergic Signal 2008;4:120.

-32 Watala C: Blood platelet reactivity and its pharmacological modulation in (people with) diabetes mellitus. Curr Pharm Des 2005;11:2331-2365.

33 Bailey AL, Campbell CL: Oral antiplatelet therapy for acute coronary syndromes: aspirin, P2Y12 inhibition and thrombin receptor antagonists. Curr Drug Targets 2011;12:1805-1812. 